\title{
Conjoint propagation and differentiation of human embryonic stem cells to cardiomyocytes in a defined microcarrier spinner culture
}

\author{
Alan Tin-Lun Lam', Allen Kuan-Liang Chen', Jian Li ${ }^{2}$, William R Birch², Shaul Reuveny ${ }^{1}$ and Steve Kah-Weng Oh ${ }^{1 *}$
}

\begin{abstract}
Introduction: Myocardial infarction is accompanied by a significant loss of cardiomyocytes (CMs). Functional CMs, differentiated from human embryonic stem cells (hESCs), offer a potentially unlimited cell source for cardiac disease therapies and regenerative cardiovascular medicine. However, conventional production methods on monolayer culture surfaces cannot adequately supply the large numbers of cells required for such treatments. To this end, an integrated microcarrier (MC) bioprocessing system for hESC propagation and subsequent CM differentiation was developed.

Methods: Production of hESC-derived CMs was initially established in monolayer cultures. This control condition was compared against hESC expansion on laminin-coated MC with cationic surface charge, in a stirred serum-free defined culture. Following expansion, the hESC/MC aggregates were placed in a CM differentiation medium, using Wnt signalling modulators in four different culture conditions. This process eliminated the need for manual colony cutting. The final optimized protocol was tested in stirred spinner flasks, combining expansion and differentiation on the same MC, with only media changes during the culture process.
\end{abstract}

Results: In the propagation phase, a 15-fold expansion of viable pluripotent HES-3 was achieved, with homogeneous sized aggregates of $316 \pm 11 \mu \mathrm{m}$. Of the four differentiation conditions, stirred spinner flask cultures (MC-Sp) provided the best controlled aggregate sizes and yielded $1.9 \times 10^{6} \mathrm{CM} / \mathrm{ml}$, as compared to $0.5 \times 10^{6} \mathrm{CM} / \mathrm{ml}$ using the monolayer cultures method: a four-fold increase in $\mathrm{CM} / \mathrm{ml}$. Similar results $\left(1.3 \times 10^{6} \mathrm{CM} / \mathrm{ml}\right)$ were obtained with an alternative hESC $\mathrm{H} 7$ line. The hESC/MC-derived CM expressed cardiac-specific transcription factors, structural, ion channel genes, and exhibited cross-striations of sarcomeric proteins, thus confirming their cardiac ontogeny. Moreover, E-4031 (0.3 $\mu \mathrm{M})$ prolonged the QT-interval duration by $40 \%$ and verapamil (3 $\mu \mathrm{M})$ reduced it by $45 \%$, illustrating the suitability of these CM for pharmacological assays.

Conclusions: We have demonstrated a robust and scalable microcarrier system for generating hESC-derived CM. This platform is enabled by defined microcarrier matrices and it integrates cell propagation and differentiation within a continuous process, in serum-free culture media. It can generate significant numbers of $\mathrm{CM}$, which are potentially suitable for future clinical therapies.

\footnotetext{
* Correspondence: steve_oh@bti.a-star.edu.sg

${ }^{1}$ Stem Cell Group, Bioprocessing Technology Institute, Agency for Science,

Technology and Research (A*STAR), Singapore 138668, Singapore

Full list of author information is available at the end of the article
} 


\section{Introduction}

Cardiovascular disease is a major cause of deaths worldwide [1]. Most of these diseases, such as ischemic heart disease and myocardial infarction, are associated with the permanent loss of heart muscle, in the form of functional cardiomyocytes (CMs) [2]. Given the limited intrinsic regenerative capacity of the mammalian heart, recent studies have focused on engineering the constituent cells for tissues that may potentially repair damaged cardiac muscle. Cells intended for clinical use need to be expanded easily in significant numbers and should differentiate into mature, fully functional CMs, capable of integrating to the damaged host tissue $[3,4]$. Human pluripotent stem cells (hPSCs), such as human embryonic stem cells (hESCs) and human induced pluripotent stem cells, offer the opportunity of a promising therapeutic approach in which functional CMs generated in vitro can be transplanted into an injured heart and restore its function [4-6].

hPSCs have been differentiated with growth factor-based [7-10] or small molecule-based [11-15] differentiation protocols. Recently, a highly efficient CM differentiation protocol was reported by Lian and colleagues $[12,13]$. The protocol uses two small molecules to modulate the Wnt signalling pathway, with early enhancement of differentiation at day 0 by 6 -bromoindirubin-3' -oxime (BIO) or CHIR99021 and subsequent repression of the Wnt pathway, from day 3, by adding inhibitor of Wnt production IWP2 or IWP4 [12]. Up to $98 \%$ cardiac troponin $\mathrm{T}$ (cTnT)-positive functional human CMs was reported for monolayer cultures (MNL) [12].

Pluripotent hESCs have been generally differentiated in two different platforms either on tissue culture plates [16-20] or embryoid body (EB) cultures [21,22]. The suspended EB cultures have the potential for volumetric scale-up [23,24], which poses significant challenges in planar tissue culture plates [25]. However, the generation of EBs involves dissociating or cutting aggregate cultures and subsequent cell reaggregation [26]. These processes are labour intensive and can affect cell viability, making the process difficult to automate and scale up. Moreover, it is hard to control aggregate sizes and shapes, and such heterogeneity therefore affects differentiation reproducibility $[27,28]$. Although EBs of controlled size can be formed by hanging drops [15] or forced aggregation methods $[29,30]$, they are limited to experiments on the scale of a research laboratory. In addition, high production costs, primarily generated by expensive growth factors [31], are not practical for large-scale manufacture. These hurdles must be overcome in developing an optimal method for production of large amounts of CMs as recently reviewed by our group [31].

Scalable methods for expansion of hPSCs on commercial microcarriers (MCs) coated with extracellular matrix proteins have been developed achieving high cell expansion (eightfold to 18-fold) in long-term, robust, suspended cultures [32-34]. hPSCs retain pluripotent markers, retain the ability to differentiate into the three primary germ layers, and exhibit normal diploid karyotypes. Recently, a defined polystyrene-based $(\approx 100 \mu$ m diameter $)$ $\mathrm{MC}$ coated with cationic poly-L-lysine (PLL) polyelectrolyte and laminin (LN) was developed by our group [35]. This defined matrix supports the expansion of HES3, H7, and IMR90 under continuous agitation from a single-cell seeding solution achieving high cell yields (14-fold, eightfold, and sevenfold cell expansion, respectively) with excellent viability (>90\%). Importantly, uniform size (320 to $420 \mu \mathrm{m}) \mathrm{hPSC} / \mathrm{MC}$ aggregates are generated during growth in agitated spinner flasks. These aggregates may be used as EBs for further differentiation into specific cell lineages, thus eliminating the need for cell dissociation, cutting, and reaggregation. Our group has similarly developed an integrated MC propagation and differentiation platform for neuroprogenitors, with yields 11.6-fold higher than those from EB culture [36].

The present study implements uniform-sized aggregates, formed during stirred spinner culture using MCs coated with PLL $+\mathrm{LN}$, to generate CMs within a continuous process, in the same culture vessel. The differentiation of these hESC/MC aggregates was directed to CMs using a differentiation protocol based on Wnt modulators $[12,13]$. Five culture regimes were evaluated, ranging from benchmarking with MNL to MC-based cultures in static conditions and under agitation (Figure 1). The efficiency of cardiac differentiation was quantified and the molecular, structural, and functional properties of hESC/MCderived CMs were also examined. This study provides a foundation for the scalable and robust production of hESC-derived CMs in large numbers, by means of a conjoint propagation and differentiation bioprocess in a defined environment, free of growth factors.

\section{Materials and methods}

\section{Microcarriers and their coatings}

Polystyrene MCs with an average diameter of $97 \pm 10 \mu \mathrm{m}$ were purchased from Thermo-Fisher Scientific (Waltham, MA, USA). These MC beads were sterilised by exposure to gamma irradiation (10 minutes, $10 \mathrm{kGray} /$ hour) in a ${ }^{60} \mathrm{Co}$ irradiator (Gammacell 200 Excel; Ottawa, ON, Canada) before being utilised for culture.

For coating with PLL (70 to $150 \mathrm{kDa}$; Sigma-Aldrich, St. Louis, MO, USA), $12 \mu \mathrm{l}$ of $1 \mathrm{mg} / \mathrm{ml}$ PLL were added to $20 \mathrm{mg} \mathrm{MC}$ in $600 \mu \mathrm{l}$ phosphate-buffered saline (PBS), to make a final PLL concentration of $20 \mu \mathrm{g} / \mathrm{ml}$. This was incubated at $4^{\circ} \mathrm{C}$ overnight and then rinsed with $\mathrm{PBS}$ before further coating. Similarly, the coating of murine LN (Life Technologies, Carlsbad, CA, USA) was achieved by adding $20 \mu \mathrm{l}$ of $1 \mathrm{mg} / \mathrm{ml} \mathrm{LN}$ to $20 \mathrm{mg}$ PLL- 


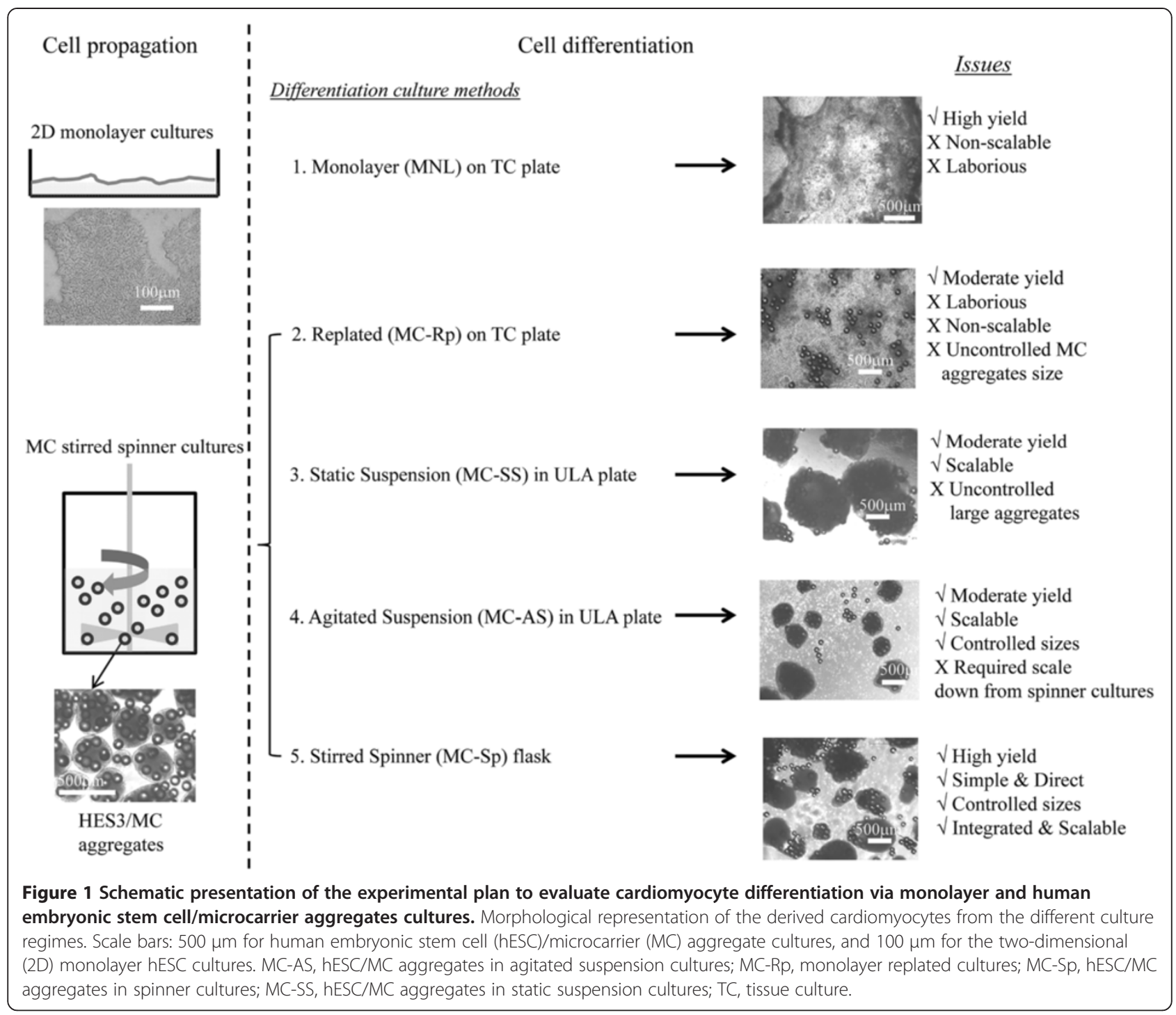

coated MC in $600 \mu \mathrm{l}$ PBS, to make a final LN concentration of $33 \mu \mathrm{g} / \mathrm{ml}$ [35]. The MCs were similarly incubated at $4^{\circ} \mathrm{C}$ overnight, followed by a rinse with PBS before being used for cell culture.

\section{Culture of human embryonic stem cells}

The HES3 ([46 X,X]; ES Cell International, Alameda, CA, USA) and H7 ([46 X,X]; WiCell Research Institute, Madison, WI, USA) cell lines were routinely maintained on Matrigel-coated plates using $\operatorname{mTeSR}^{\mathrm{Tm}} 1 \mathrm{hESC}$ medium (StemCell Technologies, Vancouver, BC, Canada) as described previously [35,37]. Cultures were incubated at $37^{\circ} \mathrm{C}$ in a humidified atmosphere with $5 \%$ carbon dioxide. Unless otherwise stated, all culture media (for cell propagation and differentiation) and supplements were purchased from Life Technologies and all reagents and chemicals were purchased from Sigma-Aldrich.
Human embryonic stem cell propagation in spinner cultures hESC MC culture was run in a $50 \mathrm{ml}$ spinner flask (BellCo, Vineland, NJ, USA), using a procedure similar to the one described previously [32,35]. Briefly, hESC/ MC aggregates from six-well ultra-low attachment plate (Costar, Tewksbury, MA, USA) cultures were mechanically dissociated into small cell clumps and seeded at $2 \times 10^{5}$ cells $/ \mathrm{ml}$ in the $50 \mathrm{ml}$ spinner flask that contained $25 \mathrm{ml} \mathrm{hESC}$ medium and $200 \mathrm{mg}$ PLL $+\mathrm{LN}$-coated MC. The sample was incubated at $37^{\circ} \mathrm{C} /$ $5 \%$ carbon dioxide for 24 hours in static conditions, after which another $25 \mathrm{ml}$ hESC medium were added and the culture was then agitated at $30 \mathrm{rpm}$ for 6 days. Eighty per cent of the spent medium was replaced daily with fresh hESC medium. The cell concentration and cell viability were determined daily using a Nucleocounter NC-3000 (Chemometec, Davis, CA, USA). Pluripotent markers were measured by flow cytometry on 
day 7. The size of the hESC/MC aggregates was measured from images taken using an Olympus IX70 microscope (Olympus, Shinjuku-ku, Tokoyo, Japan), with average dimensions determined using NIH image J software [35].

\section{Direct cardiomyocyte differentiation from propagated hESCs via temporal modulation of canonical Wht signalling}

To induce CM differentiation, the direct differentiation protocol from Lian and colleagues that uses small molecule, CHIR99021 (Selleck, Houston, TX, USA) and IWP2 (Stemgent, Cambridge, MA, USA), modulators of Wnt signalling was adopted [12,13] and optimised (see Additional file 1). This was implemented in five culture regimes (Figure 1): MNL, replated $\mathrm{hESC} / \mathrm{MC}$ aggregate cultures (MC-Rp), hESC/MC aggregates in static suspension cultures (MC-SS), hESC/MC aggregates in agitated suspension cultures (MC-AS), and hESC/MC aggregates in spinner cultures (MC-Sp). Contracting monolayers and beating aggregates were visualised daily under phase-contrast microscopy (Evos, AMG, Mill Creek, WA, USA). On day 20 of the differentiation protocol, cells from all cultures were harvested and analysed by fluorescence-activated cell sorting (FACS). The sizes of differentiated aggregates were measured using the Olympus IX70 microscope, and average sizes were determined using NIH image J software.

\section{Culture regime 1: monolayer}

A hESC single-cell suspension was obtained by dissociating confluent HES3 with TrypLE ${ }^{\mathrm{TM}}$ (Life Technologies). Viable cells $\left(4 \times 10^{5}\right.$ cells/well) from the single cell suspension were seeded into a 12-well plate (Corning, Tewksbury, MA, USA) coated with $10 \mu \mathrm{g} / \mathrm{ml} \mathrm{LN}$. The cultures were maintained in $\mathrm{mTeSR}^{\mathrm{TM}} 1 \mathrm{hESC}$ medium in a $37^{\circ} \mathrm{C} / 5 \%$ carbon dioxide incubator for 3 to 4 days, until cells reached confluence. At this point, differentiation was started by removing spent hESC medium and adding RPMI/B27 medium without insulin (referred to as differentiation medium) and containing $12 \mu \mathrm{M}$ CHIR99021 [12]. After 24 hours (that is, day 1 of differentiation), the medium was aspirated and replaced with fresh differentiation medium. On day 3 of differentiation, differentiation medium with $5 \mu \mathrm{M}$ IWP2 was added. On day 5 of differentiation, the IWP2-containing differentiation medium was removed and the medium was subsequently refreshed every 2 days, until day 11. Cells were then maintained in differentiation medium with insulin until day 20 .

\section{Culture regime 2: replated $h E S C / M C$ aggregates}

About $50 \mathrm{hESC} / \mathrm{MC}$ aggregates (equivalent to $4 \times 10^{5}$ cells/well) from spinner flask cultures were inoculated onto a $10 \mu \mathrm{g} / \mathrm{ml} \mathrm{LN-coated} \mathrm{12-well} \mathrm{plate.} \mathrm{After} \mathrm{incuba-}$ tion for 1 day to allow the aggregates to attach, the plate was washed with PBS to remove unattached aggregates. Direct differentiation was subsequently initiated by removing spent hESC medium and adding differentiation medium containing $15 \mu \mathrm{M}$ CHIR99021 (day 0). After 24 hours the differentiation medium was replenished, and $10 \mu \mathrm{M}$ IWP2 was added at day 3. This IWP2 was removed during the medium exchange on day 5. Cells were then maintained in differentiation medium with insulin from day 11 until day 20.

\section{Culture regime 3: $h E S C / M C$ aggregates in static suspension}

About $50 \mathrm{hESC} / \mathrm{MC}$ aggregates from spinner cultures were incubated in a 12-well ultra-low attachment plate (Nunc, Rochester, NY, USA) and directly subjected to cardiac differentiation simply by changing the hESC medium into CHIR99021-containing differentiation

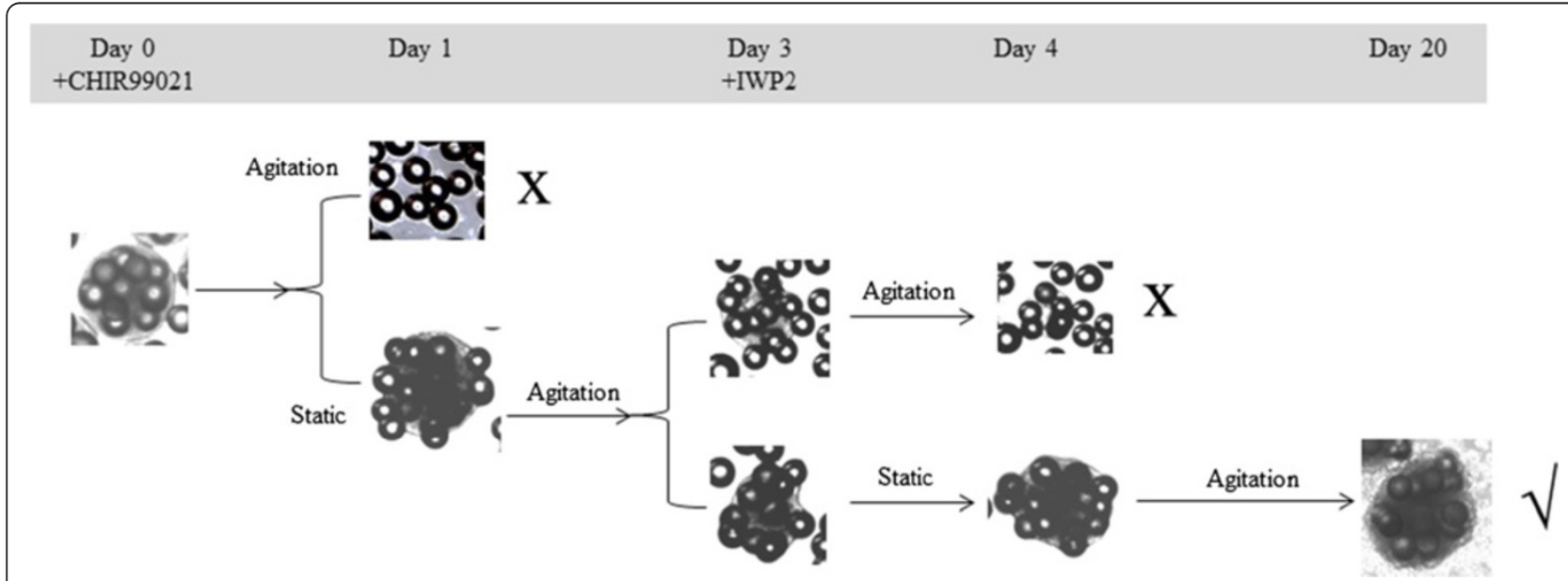

Figure 2 Effects of different agitation and static modes in the differentiation phase. Agitation at 110 rpm was applied at different periods of times. $X$, aggregate disintegration; $V$, successful aggregate growth. 
medium followed by IWP2 treatment, as described for MC-Rp above.

\section{Culture regime 4: $h E S C / M C$ aggregates in agitated suspension} The same medium was used as in MC-SS with different times for static and agitation (110 rpm) during the period of differentiation, as shown in Figure 2. The successful protocol was static on day 1, agitated on day 2, static again on day 3, and agitated for days 4 to 20 .

\section{Culture regime 5: hESC/MC aggregates in stirred spinner culture}

The best agitation protocol chosen from MC-AS was transposed to culture in a spinner flask. Briefly, hESC/ $\mathrm{MC}$ aggregates from the exponentially growing hESC MC culture $\left(1.5 \times 10^{6}\right.$ cells $\left./ \mathrm{ml}\right)$ were used. Differentiation was initiated by replacing the spent hESC medium with differentiation medium containing $15 \mu \mathrm{M}$ CHIR99021. This was incubated in static condition for 16 hours, after which the medium was replaced with fresh differentiation medium (without CHIR99021) and stirred at $30 \mathrm{rpm}$. On day 3, differentiation medium with $10 \mu \mathrm{M}$ IWP2 was introduced and incubated with a second static 16-hour pause, followed by agitation from day 4 until the end of the differentiation process (day 20). On day 5 the spent medium was replenished, and refreshed thereafter every 2 days until day 11. The culture was then fed with differentiation medium with insulin every 2 days until day 20 . Aliquots $(\sim 1 \mathrm{ml})$ of cell suspension were taken at different time points for gene expression analysis. On day 20, the culture was harvested for structural and functional analyses.

\section{Fluorescence-activated cell sorting}

To test the pluripotency of expanded hESCs, FACS was performed with the expression of the stem cell markers Tra-1-60 (Millipore, Darmstadt, Germany) and mAb84 [34] by flow cytometry as described in our previous studies [33,35].

CM differentiation efficiency was quantified by the expression of myosin heavy chain (MHC) and cTnT I. Briefly, cells harvested from day 20 were fixed and permeabilised using Fix and Perm Cell permeabilisation reagents (Life Technologies). The cells were subsequently incubated with anti-MHC (dilution 5:200; Developmental Studies Hybridoma Bank, Iowa city, IA, USA) and anticTnT (dilution 1:200; Millipore) for 20 minutes. After washing with $1 \%$ bovine serum albumin/PBS, the cells were incubated in the dark with 1:500 dilutions of antimouse FITC-conjugated secondary antibodies (dilution 1:500; DAKO, Glostrup, Denmark) for 20 minutes in the dark. The signal from labelled cells was acquired using a FACSCalibur and was analysed with FlowJo (Tree Star, Ashland, OR, USA), following the manufacturer's protocol, with gating selected at the point of intersection between the marker and its isotype control [38].

\section{Quantitative polymerase chain reaction}

Total RNA was isolated from undifferentiated (day 0) and differentiating (at different time points until day 20) hESCs from MNL and hESC/MC aggregates from MC-Sp. This isolation was accomplished using the RNeasy mini kit (Qiagen, Hilden, Germany). The yield and purity of the RNA were determined with a NanoDrop spectrophotometer (NanoDrop Technologies). RNA $(1 \mu \mathrm{g})$ was reverse transcribed into cDNA via Oligo(dT) with SuperScript III Reverse Transcriptase (Life Technologies). Real-time quantitative polymerase chain reaction was performed on an ABI7500 system (Applied Biosystems, Carlsbad, CA, USA) with Power SYBR Green PCR Master Mix (Applied Biosystems) containing the genes of interest presented in Additional file 2. Thermal cycling was applied as follows: $50^{\circ} \mathrm{C}$ for 2 minutes, $95^{\circ} \mathrm{C}$ for 10 minutes, following by 40 cycles of $95^{\circ} \mathrm{C}$ for 15 seconds and $60^{\circ} \mathrm{C}$ for 1 minute. Data were analysed and the fold-change of each gene referenced against expression of the same gene prior to cell differentiation.

\section{Metabolite measurement}

Glucose, glutamine, lactate, and ammonia concentrations in the cultures were measured using Bioprofile 100 plus (NOVA, Waltham, MA). Measurements were performed on both spent media and its replacement fresh medium after each medium change. Specific consumption and production rates of the metabolites and yield ratios were calculated as described in Chen and colleagues' paper [39], by averaging of triplicate experiments.

\section{Immunocytochemistry}

Beating hESCs from MNL and hESC/MC aggregates from MC-Sp were harvested and washed in PBS, and replated in Matrigel-coated 24-well plates (Corning), where they were cultured for 2 days. The cells were then fixed with $4 \%$ paraformaldehyde for 15 minutes at room temperature, rinsed in PBS, and permeabilised by incubation with $0.1 \%$ Trion $\mathrm{X}-100 / 1 \%$ bovine serum albumin in PBS for 1 hour at room temperature. They were then blocked for 2 hours in PBS containing 0.1\% Triton X-100, 10\% goat serum, and 1\% bovine serum albumin. Cells were then probed with primary antibodies including anti-sarcomeric $\alpha$-actinin (anti-SA; Sigma, St. Louis, MO, USA), anti-myosin light chain (Cell Signalling, Danvers, MA, USA), and anti-cTnT (Millipore) for 1 hour, followed by a secondary Alexa Fluor ${ }^{\circledR} 594$ antibody (Life Technologies) for another 2 hours at room temperature. A fluorescent mounting medium with 4',6diamidino-2-phenylindole nuclear staining (Vectashield) 
was added to cover the cells during their imaging with an Axiovert $200 \mathrm{M}$ fluorescence microscope (Carl Zeiss).

\section{QT prolongation assay by microelectrode arrays}

Beating hESC/MC aggregates were incubated with TrypLE $^{\mathrm{Tm}}$ Express (Life Technologies) for 30 minutes to dissociate the cells from microcarriers. The cell suspensions were then filtered through a 40- $\mu \mathrm{m}$ cell strainer (Becton Dickinson, San Jose, CA, USA) and placed in an ultra-low attachment U-96 plate (Costar). They were centrifuged at $1500 \mathrm{rpm}$ for 5 minutes and subsequently allowed to form EB-like aggregates for 2 to 3 days until the aggregates resumed beating contractions. The EB-like aggregates were then transferred to ReproCELL Inc., Kanagawa, Japan, who applied their QT prolongation (QTempo) assay on a microelectrode array system. A detailed description of the microelectrode array system is published elsewhere $[40,41]$. The results obtained from this system are comparable with the patch clump system [40]. Briefly, the assay consisted of plating the aggregate on a microelectrode array dish (MEA200/30iR-Ti-gr; Multi Channel Systems, Reutlingen, Germany) in QTempo assay medium supplemented with E-4031 or verapamil with increasing concentrations. Each concentration of test compound was added to the beating aggregate every 4 minutes in an accumulative assay method [38,40]. Two minutes (minutes 0 to 2) were allowed for conditioning, followed by 2 minutes (minutes 2 to 4 ) for detection, as per ReproCELL's QTempo assay protocol [40]. Commercially available induced pluripotent stem cell-derived CM (ReproCardio 2) from ReproCELL Inc. was used as positive control. QT intervals (also known as the field potential duration [42]) were determined by measuring the time interval between the beginning of the $\mathrm{Q}$ wave and the end of the $\mathrm{T}$ wave on the electrocardiogram [43]. The correction of the QT interval for the beating rate is calculated according to Bazett's formula [44].

\section{Statistical analysis}

All experiments were performed at least in triplicate. Data values are reported as the mean and standard deviation. Analysis of variance was applied as a comparison between groups, with $P<0.05$ and $P<0.01$ considered two levels of statistically significant differences.

\section{Results}

\section{Differentiation of hESCs to cardiomyocytes via} conventional monolayer cultures

HES3 cells were differentiated into CMs using a Wnt modulator-based protocol, as described by Lian and colleagues [12]. The culture matrix was LM rather than Matrigel $^{\mathrm{m}}$, however, in order to develop a defined environment that is suitable for generating and maintaining clinical-grade CMs.

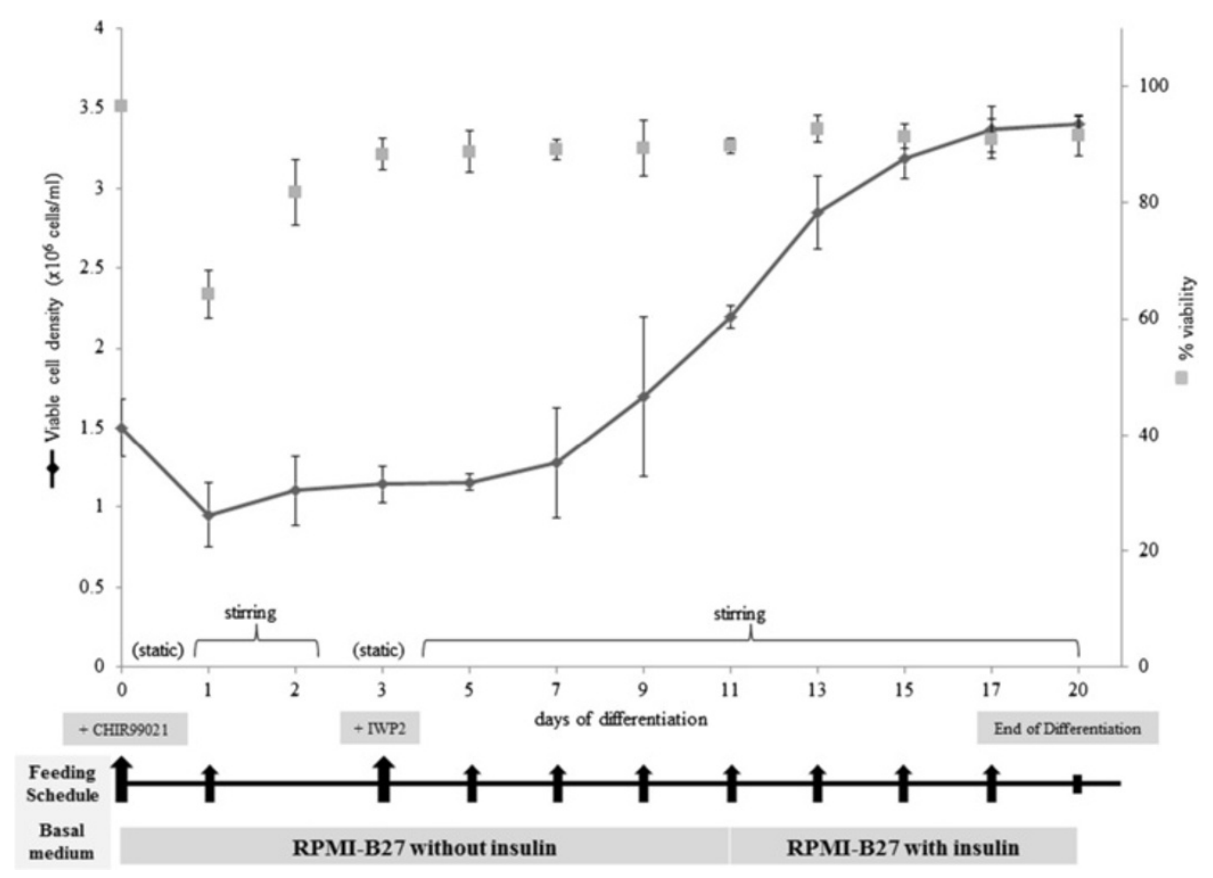

Figure 3 Growth kinetics of HES3/microcarrier aggregates differentiating in stirred spinner cultures. The cultures were incubated at $37^{\circ} \mathrm{C}$ and $5 \%$ carbon dioxide in stirring conditions, except on day 1 and day 3 in which the cultures were incubated in static conditions for 16 hours to reduce cell loss due to the addition of Wnt modulators, CHIR99021 and IWP2. Feeding regime as indicated by arrows. 
Table 1 Propagation and differentiation of HES3 to cardiomyocytes using different culture methods

\begin{tabular}{|c|c|c|c|c|c|}
\hline \multirow{2}{*}{$\begin{array}{l}\text { Culture conditions } \\
\text { Propagation (7 days) }\end{array}$} & \multirow[t]{2}{*}{ MNL hESC cultures } & \multicolumn{4}{|c|}{ hESC/MC aggregate spinner cultures } \\
\hline & & & & & \\
\hline Expansion fold (propagation) & $10.3 \pm 0.4$ & $15.4 \pm 0.4$ & & & \\
\hline \multicolumn{6}{|l|}{ \% Pluripotent cells } \\
\hline Tra-1-60-positive & $93.1 \pm 1.4$ & $96.2 \pm 1.7$ & & & \\
\hline mAb84-positive & $99.4 \pm 0.5$ & $98.6 \pm 1.7$ & & & \\
\hline Aggregate sizes ( $\mu \mathrm{m})$ & NA & $316 \pm 11$ & & & \\
\hline \multicolumn{6}{|l|}{ Differentiation to cardiomyocytes (20 days) } \\
\hline & $\mathrm{MNL}$ & MC-Rp & MC-SS & MC-AS & MC-Sp \\
\hline Expansion fold (differentiation) & $2.0 \pm 0.2$ & $2.2 \pm 0.1$ & $2.1 \pm 0.2$ & $2.0 \pm 0.2$ & $2.3 \pm 0.1$ \\
\hline$\%$ beating aggregates & Beating sheet & $65.7 \pm 1.8$ (beating foci on plate) & $66.5 \pm 2.6$ & $53.4 \pm 1.5$ & $73.6 \pm 2.8$ \\
\hline Beating aggregate size $(\mu \mathrm{m})$ & NA & NA & $1063 \pm 53$ & $581 \pm 54$ & $655 \pm 13$ \\
\hline \multicolumn{6}{|l|}{$\%$ Cardiomyocytes } \\
\hline MHC-positive & $45.7 \pm 4.6$ & $43.1 \pm 1.2$ & $42.6 \pm 1.9$ & $42.8 \pm 1.6$ & $47.7 \pm 1.9$ \\
\hline cTnT-positive & $51.1 \pm 0.5$ & $53.1 \pm 0.9$ & $45.7 \pm 2.9$ & $42.4 \pm 0.2$ & $56.1 \pm 1.4$ \\
\hline CM/hESC & $3.8 \pm 0.2$ & $1.2 \pm 0.2$ & $1.0 \pm 0.2$ & $0.8 \pm 0.1$ & $9.6 \pm 0.3^{\mathrm{a}}$ \\
\hline $\mathrm{CM} / \mathrm{ml}\left(\times \times 10^{6}\right)$ & $0.5 \pm 0.02$ & $0.2 \pm 0.02$ & $0.1 \pm 0.02$ & $0.1 \pm 0.01$ & $1.9 \pm 0.05^{b}$ \\
\hline Total expansion fold (propagation + differentiation) & $20.0 \pm 0.8$ & $32.8 \pm 1.1$ & $31.8 \pm 2.1$ & $29.3 \pm 2.5$ & $34.3 \pm 0.9^{c}$ \\
\hline
\end{tabular}

HES3 cells were propagated as either monolayer cultures (MNL) or human embryonic stem cell (hESC)/microcarrier (MC) aggregates for 7 days. Five differentiation

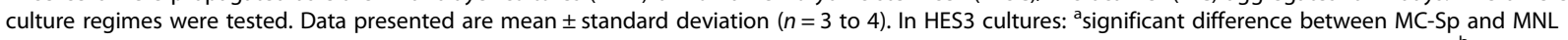
$(P<0.05)$, and between MC-Sp and the other three regimes $(P<0.01)$, in terms of cardiomyocytes produced per initial hESC seeded $(C M / h E S C)$; ${ }^{b}$ significant differences $(P<0.01)$ between MC-Sp and the other four regimes in terms of cardiomyocyte density $(\mathrm{CM} / \mathrm{ml}) ;{ }^{\mathrm{C}}$ significant difference between $\mathrm{MC}-\mathrm{Sp}$ and $\mathrm{MNL}$ $(P<0.05)$ in terms of total expansion fold achieved. $C M$, number of cardiomyocytes (cTnT-positive cells) in the final cell population; Total expansion fold, cell expansion from seeding the hESC culture in the propagation phase, to final CM harvesting (day 20) in the differentiation phase. CTnT, Cardiac troponin T; MC-AS, $\mathrm{hESC} / \mathrm{MC}$ aggregates in agitated suspension cultures; MC-Rp, monolayer replated cultures; MC-Sp, hESC/MC aggregates in spinner cultures; MC-SS, hESC/MC aggregates in static suspension cultures; MHC, myosin heavy chain; NA, not available.

For MNL, the optimal concentrations of CHIR99021 and IWP2 for cardiac differentiation were $12 \mu \mathrm{M}$ and $5 \mu \mathrm{M}$, respectively (see Figure S1A in Additional file 1). Spontaneously contracting regions were readily observed at 8 days' differentiation. The numbers of contracting foci increased with time, and at day 20 these were observed over almost the entire well (see Additional file 3). These foci appeared to be loosely attached to the plate. On day 20 of differentiation, total cell expansion (cell expansion from seeding the hESC culture in the propagation phase to final CM harvesting in the differentiation phase) was $20 \pm 0.8$-fold. Furthermore, $45.7 \pm 4.6 \%$ of cells were MHC-positive and $51.1 \pm 0.5 \%$ were cTnT-positive as measured by FACS (Table 1). The overall CM yield was $3.8 \pm 0.2 \mathrm{CM} / \mathrm{hESC}$, with a final cell concentration of $0.5 \pm 0.02 \times 10^{6} \mathrm{CM} / \mathrm{ml}$.

\section{Differentiation of spinner culture expanded hESC/MC aggregates into cardiomyocytes by four different approaches}

HES3 cells were first propagated on PLL + LN-coated MCs in $\mathrm{mTeSR}^{\mathrm{Tm}} 1$ for 7 days on MC cultures in $50 \mathrm{ml}$ stirred spinner flasks. Similarly to our previous work [35], exponential cell growth started on day 4, with a maximum cell density of $\sim 3 \times 10^{6}$ cells $/ \mathrm{ml}$ attained at day 7. Cell viability was above 90\% (see Figure S2A in Additional file 4$)$, with high expression (>90\%) of pluripotent markers Tra-1-60 and mAb84 (Table 1). Spherical hESC/MC aggregates (EB-like), $316 \pm 11 \mu \mathrm{m}$ in size, were generated (Table 1; see Figure S2A in Additional file 4).

After cell propagation, four methods of differentiation for cardiogenesis efficiency were investigated by modulating Wnt [12,13] - replated hESC/MC aggregates on LN-coated plates (MC-Rp); hESC/MC aggregates in static suspension (MC-SS); hESC/MC aggregates in agitated suspension (MC-AS); and hESC/MC aggregates in spinner cultures (MC-Sp) - as illustrated in Figure 1.

\section{Replated hESC/MC aggregates}

hESC/MC aggregates attached and subsequently spread within 3 to 4 days, forming a flattened configuration on the LN-coated surface. About $50 \%$ of the MCs were released to culture supernatant after cell plating and during differentiation. Beating clusters were first observed as early as day 8, following incubation with $15 \mu \mathrm{M}$ CHIR99021 and $10 \mu \mathrm{M}$ IWP2 (see Figure S1B in Additional file 1 ). On day $20,65.7 \pm 1.8 \%$ of beating clusters, lying on beating sheets were scored. Total CM yield was $1.2 \pm 0.2 \mathrm{CM} / \mathrm{hESC}$ and density was $0.2 \pm 0.02 \times 10^{6}$ 
$\mathrm{CM} / \mathrm{ml}$, lower than those from MNL cultures $(P<0.05)$. However, the total expansion was $32.8 \pm 1$.1-fold, higher than that in MNL (20.0 \pm 0.8 -fold; $P<0.05$; Table 1$)$.

\section{hESC/MC aggregates in static suspension}

Despite the optimal concentrations of CHIR99021 and IWP2 (see Figure S1C in Additional file 1) being used, which were the same as for MC-Rp, beating aggregates were observed later, around day 12 of differentiation. On day 20, the $\mathrm{CM}$ density was $0.1 \pm 0.02 \times 10^{6} \mathrm{CM} / \mathrm{ml}$. Moreover, uncontrolled agglomeration of cell aggregates was observed, resulting in the formation of large aggregates, $1,063 \pm 53 \mu \mathrm{m}$ in size (Table 1). In terms of total expansion, the percentage of beating aggregates scored, and the fraction of MHC-positive and cTnT-positive cells stained, MC-SS yielded similar results to MC-Rp (Table 1).

\section{hESC/MC aggregates in agitated suspension}

To prevent the formation of very large aggregates during the differentiation phase of MC-SS, agitation at $110 \mathrm{rpm}$ was applied. However, the induced shear stress resulted in massive cell detachment 1 day after adding CHIR99021 (Figure 2). To mitigate this, a static pause (optimally $\sim 16$ hours) was introduced after the addition of CHIR99021. This was followed by 2 days of agitation and another static pause ( 16 hours) when IWP2 was added, since aggregate dissociation was observed if the culture was continuously agitated (Figure 2). After these two periods, the culture was placed under continuous agitation. At day 20, 53.4 \pm $1.5 \%$ of aggregates were beating, $42.8 \pm 1.6 \%$ of cells were MHC-positive, and $42.4 \pm 0.2 \%$ of cells were cTnT-positive, yielding $0.8 \pm 0.1 \mathrm{CM} / \mathrm{hESC}$, and a cell concentration of $0.1 \pm 0.01 \times 10^{6} \mathrm{CM} / \mathrm{ml}$, similar to the $\mathrm{CM}$ yield from MC-SS, but with smaller beating aggregates $(581 \pm 54 \mu \mathrm{m})$ (Table 1).

To summarise, we demonstrated that hESC/MC aggregates can serve as EBs for cardiac differentiation with higher differentiation efficiency. The efficiency between the three culture regimes did not vary to a great extent (0.8 to $1.2 \mathrm{CM} / \mathrm{hESC}$; Table 1 ). To implement this protocol in bioreactors used for industrial manufacturing, a regime consisting of agitation with intermittent static pauses was introduced. This culture regime retained intact aggregates for differentiation and was applied therefore for direct differentiation in a stirred spinner flask.

\section{hESC/MC aggregates in spinner cultures}

After demonstrating the feasibility of generating CMs using $\mathrm{hESC} / \mathrm{MC}$ aggregates in agitated small plates, the next step was to accomplish a conjoint propagation and differentiation process in a stirred spinner flask (MC-Sp). At day 20 of differentiation, this method yielded $73.6 \pm$ $2.8 \%$ of beating aggregates (see Additional file 5). Their average size was $655 \pm 13 \mu \mathrm{m}$, approximately twice the linear dimensions $(316 \pm 11 \mu \mathrm{m})$ of aggregates during the expansion phase (Table 1). FACS analysis showed that up to $47.7 \pm 1.9 \%$ of cells were MHC-positive and $56.1 \pm 1.4 \%$ of cells were cTnT-positive. This yielded $9.6 \pm 0.3 \mathrm{CM} / \mathrm{hESC}$, about 2.5 times higher than the MNL cultures $(3.8 \pm 0.2$ $\mathrm{CM} / \mathrm{hESC} ; \mathrm{P}<0.05)$ and eight to 12 times higher than the MC-Rp, MC-SS and MC-AS (1.2 $\pm 0.2,1.0 \pm 0.2$, and $0.8 \pm$ $0.1 \mathrm{CM} / \mathrm{hESC}$, respectively; $P<0.01)$. A CM concentration of $1.9 \pm 0.05 \times 10^{6} \mathrm{CM} / \mathrm{ml}$ was achieved, about four times higher than the MNL $\left(0.5 \pm 0.02 \times 10^{6} \mathrm{CM} / \mathrm{ml} ; P<0.01\right)$, nine times higher than the MC-Rp $\left(0.2 \pm 0.2 \times 10^{6} \mathrm{CM} / \mathrm{ml}\right.$; $P<0.01)$, and 19 times higher than the MC-SS and MCAS (around $0.1 \times 10^{6} \mathrm{CM} / \mathrm{ml} ; P<0.01$ ) (Table 1 ).

\section{Cell growth kinetics}

The kinetics of HES3 cell growth during the differentiation phase is shown in Figure 3. At day 1 of static culture (after addition of CHIR99021), about 30\% cell death occurs and cell density gradually increased thereafter. The lag phase, before the onset of rapid cell expansion, lasts about 3 to 4 days. This is similar to that observed for the expansion phase of HES3 on MC in spinner flasks (see Figure S2A in Additional file 4). Concomitantly during this lag phase, lower expression of octamer-binding transcription factor (OCT4) and a higher expression of Brachyury T were observed (Figure 4). This may signal the beginning of differentiation, with lower hESC pluripotency and increasing mesoderm progenitors [45]. The onset of exponential cell growth occurred between days 5 and 7 , and maximum cell density $\left(\sim 3.4 \times 10^{6}\right.$ cells $/ \mathrm{ml}$ ) was reached on day 17 , followed by a stationary phase in cell expansion. The doubling time was $128 \pm$ 14 hours during the differentiation phase, as compared with $27 \pm 2$ hours during the expansion phase (Table 2; $P<0.001)$.

A second hESC cell line, H7, was used to test this conjoint propagation (see Figure S2B in Additional file 4) and differentiation platform (see Additional file 6). H7 cells propagated on PLL + LN MC cultures achieved cell yields of $\sim 2.3 \times 10^{6}$ cells $/ \mathrm{ml}$ (see Figure S2B in Additional file 4) or 12-fold cell expansion, generating hESC/MC aggregates with dimensions of $418 \pm 17 \mu \mathrm{m}$ (see Additional file 7). H7/MC aggregates subsequently differentiated into CMs showed a similar differentiation pattern to HES3, yet achieved a cell density of $\sim 3 \times 10^{6}$ cells $/ \mathrm{ml}$ (see Additional file 6), with a doubling time of $151 \pm 1$ hours (Table 2). H7/MC aggregates during the differentiation phase were larger than the HES3/MC aggregates (Table 1 vs. Additional file 7). The size of the aggregates may influence the differentiation efficiency $[27,29,38]$, giving rise to a final output of $6.6 \pm 0.4 \mathrm{CM} / \mathrm{hESC}$ initially seeded in the culture and a cell concentration of $1.3 \pm 0.09 \times 10^{6} \mathrm{CM} / \mathrm{ml}$ 


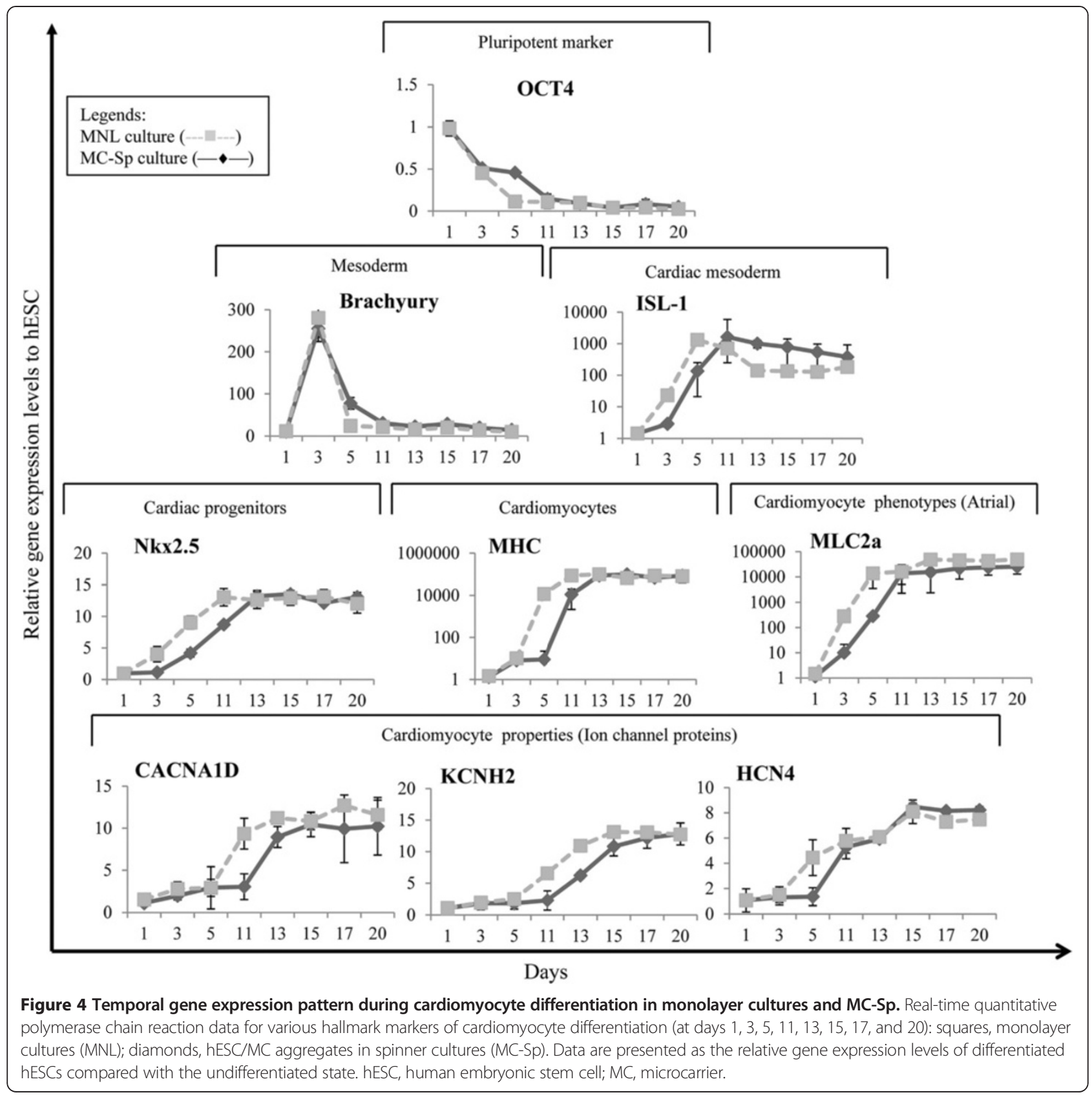

(see Additional file 7), lower than those obtained for HES3 MC-Sp (Table 1).

\section{Metabolic measurements}

Data for the consumption of glucose and glutamine as well as the production of lactate and ammonia were measured for HES3 and H7 in the expansion and differentiation phases of MC-Sp, as shown in Table 2. The metabolic activity of both hESC lines was considerably lower during the differentiating phase, with respect to their expansion phase. The molar ratio of produced lactate to consumed glucose, $\mathrm{Y}_{\mathrm{Lac}} / \mathrm{Glc}$, is almost 2 $(1.72 \pm 0.14)$ during the HES3/MC expansion phase. This indicates that cell respiration was mostly anaerobic [46], as compared with the differentiation phase, where a lower $\mathrm{Y}_{\mathrm{Lac}} /_{\mathrm{Glc}}(1.34 \pm 0.04)$ suggests that cells tend to generate ATP through oxidative phosphorylation via aerobic metabolism. In contrast, values of $\mathrm{Y}_{\mathrm{Amm} / \mathrm{Gln}}$ in both the expansion and differentiation phases were similar $(0.80 \pm 0.02$ and $0.70 \pm 0.04$, 
Table 2 Doubling times, specific metabolic rates and yield ratios of hESCs in MC-Sp in propagation and differentiation phases

\begin{tabular}{|c|c|c|c|c|}
\hline & \multicolumn{2}{|l|}{ HES3 cultures } & \multicolumn{2}{|l|}{ H7 cultures } \\
\hline & Propagation & Differentiation & Propagation & Differentiation \\
\hline Double time (hours) & $27 \pm 2$ & $128 \pm 14$ & $28 \pm 2$ & $151 \pm 1$ \\
\hline \multicolumn{5}{|c|}{ Specific consumption and production rate ( $\mathrm{mmol} / 10^{9}$ cells/hour) } \\
\hline qGlc & $0.36 \pm 0.04$ & $0.24 \pm 0.02$ & $0.34 \pm 0.05$ & $0.18 \pm 0.02$ \\
\hline qLac & $0.63 \pm 0.12$ & $0.32 \pm 0.02$ & $0.57 \pm 0.08$ & $0.23 \pm 0.01$ \\
\hline qGln & $0.036 \pm 0.003$ & $0.033 \pm 0.001$ & $0.028 \pm 0.006$ & $0.029 \pm 0.003$ \\
\hline qAmm & $0.029 \pm 0.003$ & $0.023 \pm 0.002$ & $0.019 \pm 0.005$ & $0.016 \pm 0.002$ \\
\hline \multicolumn{5}{|l|}{ Yield ratio } \\
\hline$Y_{\text {Lac/Glc }}$ & $1.72 \pm 0.14^{*}$ & $1.34 \pm 0.04^{*}$ & $1.66 \pm 0.01^{*}$ & $1.27 \pm 0.06^{*}$ \\
\hline$Y_{A m m / G l n}$ & $0.80 \pm 0.02$ & $0.70 \pm 0.04$ & $0.67 \pm 0.03$ & $0.55 \pm 0.01$ \\
\hline
\end{tabular}

Glucose (Glc), lactate (Lac), glutamine (Gln), and ammonia (Amm) were measured using Bioprofile 100 plus. Specific consumption and production rates of the metabolites $\left(\mathrm{q}_{\mathrm{m}}\right)$ were expressed as number of moles of metabolite consumed or produced per cells in one hour. Yield ratio $\left(\mathrm{Y}_{\mathrm{a}} / \mathrm{b}\right)$ was calculated by the value of $\mathrm{q}_{\mathrm{a}}$ over $\mathrm{q}_{\mathrm{b}} \cdot{ }^{*} P<0.05$ indicated there is a significant difference between the values of $Y_{\text {Lac }} / \mathrm{Glc}$ in the propagation phase and the differentiation phase in both HES3 and $\mathrm{H} 7$ cultures. MC-Sp, human embryonic stem cell/microcarrier aggregates in spinner cultures.

respectively), which fall within a range expected for mammalian cells $(0.7$ to 0.84$)$ [39,46]. Similar results were observed for $\mathrm{H} 7 \mathrm{MC}-\mathrm{Sp}$.

\section{Molecular and structural characterisation}

The dynamics of gene expression in hESC/MC aggregates, during the differentiation phase of MC-Sp, and in hESCs from differentiation MNL were monitored by quantitative polymerase chain reaction. The cardiac gene expression profile of the CMs derived from MNL (Figure 4) is similar to the profile reported in the literature [12]. The kinetic trends of all gene expression are similar in both MNL and
MC-Sp. However, a delay in the decline of the pluripotency marker and an increase of cardiac mesoderm as well as progenitor gene expression was observed in MC-Sp. The onset of CM differentiation was marked by a decrease in the pluripotency marker, OCT4, following the replacement of culture medium with differentiation medium (containing CHIR99021) at day 0. This marker decreased to negligible levels by day 11 . The expression of mesoderm marker, Brachyury $\mathrm{T}$, was transient. It peaked on day 3 and returned to its baseline expression by day 11 . This simultaneous decrease in OCT4 and increase in Brachyury $\mathrm{T}$ was observed during the lag phase (day 3 to

A $\mathrm{CM}$ from MNL cultures
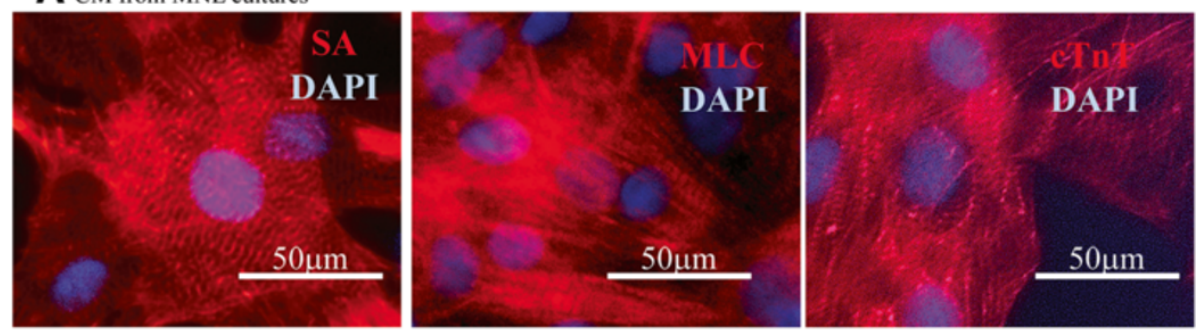

B CM from MC-Sp cultures
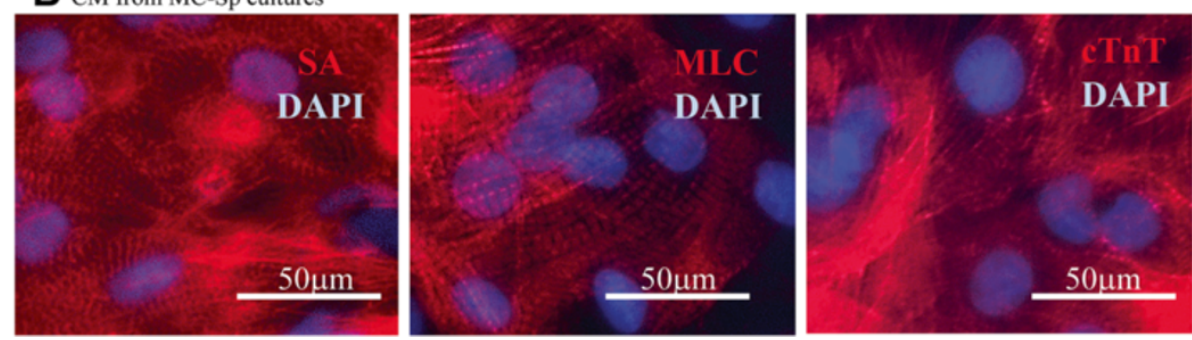

Figure 5 Immunostaining of structural proteins in monolayer cultures and MC-Sp. Immunostaining of structural proteins in (A) monolayer cultures (MNL) and (B) hESC/MC aggregates in spinner cultures (MC-Sp). Nuclei were stained with 4',6-diamidino-2-phenylindole (DAPI) (blue). Scale bar represents $50 \mu \mathrm{m}$. CM, cardiomyocytes; CTnT, cardiac troponin T; hESC, human embryonic stem cell; MC, microcarrier; MLC, myosin light chain; SA, sarcomeric a-actinin protein. 
day 5) of cell growth (Figure 3). A subsequent increase in expression of the cardiac mesoderm marker Islet- 1 and early cardiac marker homeobox protein $\mathrm{Nkx}-2.5$ began on day 3. This expression then reached its peak at day 11 and saturated on day 13. Thereafter, the relative expression of late cardiac markers such as $\alpha-\mathrm{MHC}$ was also significantly upregulated from day 5 and persisted throughout the 20 days' differentiation. A high expression of myosin light chain-2 atrial, which reached its maximum on day 11, indicated the presence of atrial CMs. The expression of cardiac ion channel proteins (CACNA1D, encoding the $\alpha 1 \mathrm{D}$ subunit of the L-type calcium channel; $\mathrm{KCNH} 2$, the potassium voltage-gated channel; and HCN4, the potassium/sodium hyperpolarisation-activated cyclic nucleotide-gated channel 4 , responsible for the pacemaker current) was also significantly upregulated after day 11 of the differentiation phase.

Immunofluorescence analyses were performed to determine the presence of cardiac-specific proteins at day 20. The hESC monolayer-derived CMs (Figure 5A) and hESC/MC-derived CMs (Figure 5B) both stained positive for sarcomeric proteins $-\alpha$-actinin, myosin light chain, and $\mathrm{cTnT}$ - thus showing a well-organised sarcomeric structure, a phenomenon associated with maturing CMs.

\section{Functional characterisation}

Beating CMs from cultures at day 20 were seeded onto a multielectrode plate, which served to test their response to pharmacologically active compounds. When the selective hERG inhibitor E-4031 was introduced, a dosedependent prolongation of the QT interval was observed from a threshold of $10 \mathrm{nM}$, peaking at $300 \mathrm{nM}$ (rising to over $140 \%$ from 100\%; Figure 6). In contrast, verapamil (L-type calcium channel blocker) induced a dosedependent reduction of the QT interval at concentrations ranging from $10 \mathrm{nM}$ to $3 \mu \mathrm{M}$ to $56 \%$ of the starting condition (Figure 6). Similar responses were observed using the induced pluripotent stem-derived cell line ReproCardio 2 (see Additional file 8). It is important to note that the QTinterval duration is directly proportional to the action potential duration in cardiomyocytes $[42,43,47]$. These results demonstrated that $\mathrm{hESC} / \mathrm{MC}$-derived $\mathrm{CMs}$ generated by MC-Sp responded normally [40] to these antiarrhythmic drugs.

\section{Discussion}

A recent review by our group discussed in detail the key issues for large-scale production of human CMs from hPSCs [31]. One of the limitations of differentiating

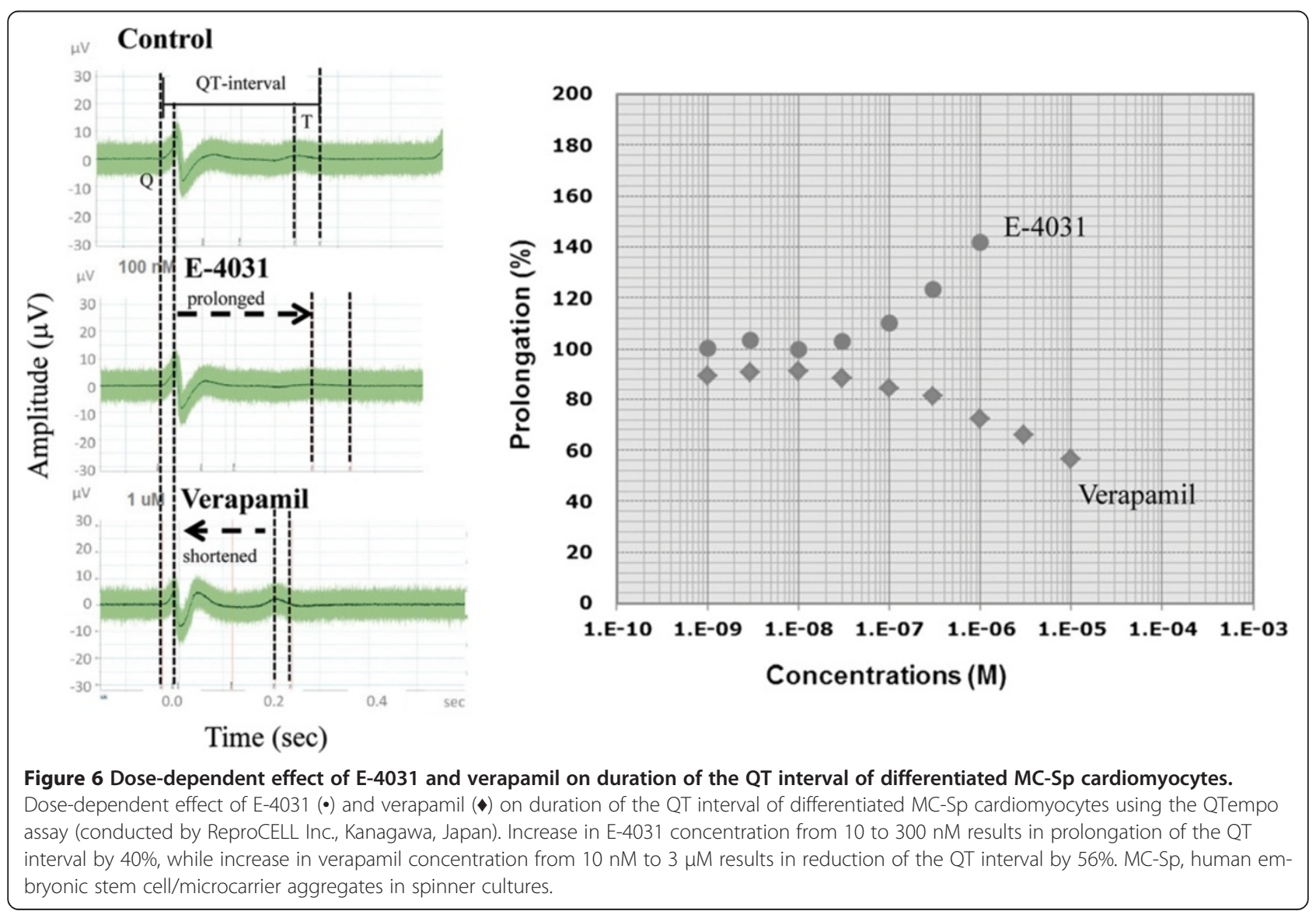


hPSCs to CMs is the low cell expansion, twofold to fivefold $[31,48]$. This is similar to our data from the present study, showing about twofold expansion (Table 1; see Additional file 7). The strategy for CM production would thus be biphasic, involving hESC propagation to generate significant cell numbers, followed by differentiation to CMs. Two hESC propagation platforms (Figure 1) were used in this study: monolayer and MC/aggregate hESC cultures. Conventional MNL have been widely employed for hESC expansion, but the increase in cell density is restricted to the available culture area $[31,34]$. MCs are characterised by high surface-to-volume ratio, which allows for high-density cell culture, and the possibility of scaling up has been demonstrated by several groups using spinner flasks $[31,34,49,50]$. The present study demonstrates that MC spinner cultures achieved 15.4-fold pluripotent HES3 expansion (similar to our previous study [35]), which is fivefold more than those achieved in MNL (Table 1). There is further room for improvement in this scalable process through controlled feeding strategies to obtain higher cell expansion [36].

Having established a scalable hESC propagation method, a suitable CM differentiation platform should be developed [31]. The present report compares five modes of differentiation, where the $\mathrm{CM} / \mathrm{hESC}$ yield was ranked as follows: $\mathrm{MC}-\mathrm{Sp}>>\mathrm{MNL}>(\mathrm{MC}-\mathrm{Rp} \approx \mathrm{MC}-\mathrm{SS})>\mathrm{MC}-\mathrm{AS}$ (Table 1). The conjoint propagation and differentiation protocol (MC-Sp) eliminates the labour-intensive cutting, size control, and replating that are required by EB culture methods [26-28]. hESC/MC aggregates (about 300 to $400 \mu \mathrm{m}$ in size) obtained during the propagation phase are subjected to a differentiation medium by continuing in the same culture vessel. A simple medium change thus induces the CM differentiation process from HES3 to generate c'TnT-positive CMs $(9.6 \pm 0.3 \mathrm{CM} / \mathrm{hESC}$ in MC-Sp vs. $3.8 \pm 0.2 \mathrm{CM} / \mathrm{hESC}$ in MNL; $P<0.05)$ and the concentration of CMs obtained $\left(1.9 \pm 0.05 \times 10^{6} \mathrm{CM} / \mathrm{ml}\right)$ was fourfold higher than from MNL $\left(0.5 \pm 0.02 \times 10^{6} \mathrm{CM} / \mathrm{ml}\right.$; $P<0.01$ ) (Table 1).

Moreover, the total cell expansion (from seeding hESC culture to final CM harvesting) in this integrated system was about 34.3-fold, whereas in MNL the expansion was 20 -fold $(P<0.05$; Table 1$)$. These differences are mainly attributed to the three-dimensional nature of the aggregate cultures as compared with the one-layer twodimensional nature of the MNL. The MC-based method lends itself easily to scalable bioreactor processing, in contrast to planar MNL, which require complex stacking arrangements and are thus poorly suited for scalable processes. hESC/MC-derived CMs from MC-Sp cultures were observed to express cardiac markers associated with cardiomyogenesis (Figures 4 and 5B), demonstrating a similar trend to that observed in hESCs differentiating on MNL (Figures 4 and 5A) and followed the cardiac developmental process [51,52]. This MC-based conjoint propagation and differentiation system is thus overall more efficient than MNL for the high-yield production of CMs in a reliable and robust process.

Prior studies demonstrated the significant role of uniform-sized cell aggregates in differentiation outcomes $[27,29,38]$. Reports from Zandstra's group suggested that the optimal aggregate size ranges from 200 to $800 \mu \mathrm{m}$, where the highest percentage of contracting aggregates is produced by $400 \mu \mathrm{m}$ aggregates [53,54]. Another study showed that the generation of $300 \mu \mathrm{m}$ aggregates, using microwells, was the most efficient method for producing contracting cells [29]. Studies by our group also suggested that a size distribution of 200 to $400 \mu \mathrm{m}$ generally gives higher cell expansion and more $\mathrm{MHC}^{+} / \mathrm{SA}^{+}$cells [38]. However, that same study generated hPSC/MC aggregates in spinner cultures from MNL, following a differentiation protocol using SB203580, a mitogen-activated protein kinase inhibitor. In short, another advantage of the present MC-based system is its ability to generate aggregates with specific sizes $(316 \mu \mathrm{m}$ in HES3, Table 1 ; and $418 \mu \mathrm{m}$ in H7, see Additional file 7). More importantly, the ability to control the size of an aggregate within a scalable bioprocess may contribute to a more homogeneous [35], synchronised differentiation [27,29,30].

A decline in cell density and viability was observed following the initial exposure of both HES3/MC and H7/ MC aggregates to CHIR99021, in MC-Sp (Figure 3 and see Additional file 6). The observed cell loss may be attributed to the abrupt change in culture medium, from $\mathrm{mTeSR}^{\mathrm{TM}} 1$, to differentiation medium (RPMI/B27), as well as the toxicity of CHIR99021, when used at high concentrations $(>10 \mu \mathrm{M})$ [55]. This cell loss could be alleviated when static pauses were employed (Figure 2), in order to prevent additional agitation-induced cell death due to further stress arising from turbulent eddies, MC-to$\mathrm{MC}$ impacts and MC-to-container (or impeller) impacts [56]. Dissociation of cells/MC aggregates were also observed after addition of IWP2 (Figure 2). Studies showed that IWP2 blocks Wnt protein secretion, leading to the proteasome-mediated degradation of $\beta$-catenin; and this is detrimental to the adherent junctions in cell-cell adhesion complexes $[57,58]$. A second static pause ( 16 hours) was thus introduced to mitigate the possibility of cells dislodgement from the $\mathrm{MC}$ due to agitation forces. In a nutshell, these two static pauses successfully maintained a stable increase in the viable cell density during the differentiation phase (Figures 2 and 3; see Additional file 6).

Although agitated MC-AS and MC-Sp are both amenable to control the size of the differentiating cell aggregates, lower cell yields were obtained in MC-AS (0.1 vs. $1.9 \times 10^{6} \mathrm{CM} / \mathrm{ml}, P<0.01$; Table 1$)$. This is attributed to the high agitation speeds of the plates on a shaking platform (110 rpm to suspend $\mathrm{hESC} / \mathrm{MC}$ aggregates) 
potentially generating higher hydrodynamic forces than the gentle agitation by an impeller, operating at lower speed $(30 \mathrm{rpm})$, in stirred flasks [59]. This putatively resulted in poorer hESC growth and differentiation efficiency, as measured in MC-AS [60]. Moreover, cells can be seeded at 10 -fold higher density $\left(\sim 1.5 \times 10^{6}\right.$ cells $\left./ \mathrm{ml}\right)$ in MC-Sp, than the inoculum cell density in MNL, MC$\mathrm{Rp}, \mathrm{MC}-\mathrm{SS}$, or MC-AS $\left(\sim 1.5 \times 10^{5}\right.$ cells $\left./ \mathrm{ml}\right)$. In addition, the well-mixed environment of $\mathrm{MC}-\mathrm{Sp}$ is better for delivering nutrients and oxygen to $\mathrm{MC}$ cell aggregates via convection of the fluid medium $[59,61]$. High cell viability is thus maintained without compromising the differentiation efficiency, resulting in higher CM yields. The present study further confirms previous work from our group, describing that microcarrier cultures facilitate higher pluripotent and differentiated cell (neuroprogenitors) yields [32,34-36].

Quantification of the nutrient uptake and respiration products offers evidence that the hESC energy metabolism differs between the propagation and differentiation phases. In the hESC propagation phase, the higher $\mathrm{Y}_{\mathrm{Lac} / \mathrm{Glc}}$ indicates anaerobic glycolysis (Table 2). Reports state that stem cells favour anaerobic glycolysis for cell survival and proliferation, but not differentiation, since they only possess immature mitochondria for energy supply in order to control the stem cell state [62,63]. In contrast, lower $\mathrm{Y}_{\text {Lac/Glc }}$ (1.27 to 1.34; Table 2) during cell differentiation suggests that this phase is accompanied by an increase in the aerobic metabolism of the cells. Reports have shown that differentiation events are associated with the proliferation of mitochondria, which generate more energy for the molecular machinery in response to differentiation $[64,65]$. Another study has demonstrated that the inhibition of Wnt signalling facilitates mitochondrial respiration, with induction of the glycolytic switch into an aerobic metabolism [66]. This correlates with the findings of the present study.

This platform may potentially be improved to obtain higher yields and purity of CM cells for clinical applications; for example, by altering the feeding regime to daily or twice-daily medium exchange [36]. Moreover, the addition of ascorbic acid has been demonstrated to promote cardiac differentiation and has been applied in several protocols, using hESCs and human induced pluripotent stem cells $[14,67]$. To implement good manufacturing practice production criteria, human LM could replace murine LM for propagating and differentiating hESCs in a serum-free, xeno-free, defined environment. Depending on the size of the bioreactor, larger quantities of clinical-grade CMs can thus be generated to meet therapeutic dose requirements.

\section{Conclusion}

Five methods of differentiation were compared and $\mathrm{MC}$ Sp were the best condition for scale-up and production of hESC-derived CMs, within an integrated process of cell propagation and subsequent differentiation. This MCbased conjoint culture is crucial to achieving both high cell densities $\left(1.9 \times 10^{6} \mathrm{CM} / \mathrm{ml}\right)$ and high $\mathrm{CM} / \mathrm{hESC}$ yields $(9.6 \pm 0.3)$, as compared with the other tested methods. CMs expressed cardiac-specific transcriptional factors, structural and functional genes, and generation of crossstriated muscle structure that recapitulate the development ontogeny of cardiogenesis. The advantages of this approach are: high cell yields; controlled aggregate size; negligible labour-intensive manual intervention (timesaving); and use of cost-effective defined chemical components (a potential cost-saving), which has the potential to comply with a defined good manufacturing practice bioprocess system. The scalable nature of this MC-based bioprocess under agitation is expected to provide a platform technology for the bioreactor-based production of $\mathrm{CMs}$ derived from hPSCs.

\section{Additional files}

Additional file 1: Is a figure showing optimization of the concentrations of Wnt modulators, CHIR99021 and IWP2, in MNL (A); MC-Rp (B); and MC-SS (C). Cells were analysed for MHC and CTnT expression by flow cytometry 20 days after initiation of differentiation. The optimal concentrations are marked in the white box. Step 1: optimization of CHIR99021 concentration (IWP2 concentration kept at $5 \mu \mathrm{M}$ ); Step 2: optimization of IWP2 concentrations (the optimal concentrations of CHIR99021 were used in Step 1).

Additional file 2: Is a table presenting the sequences of primers used for quantitative polymerase chain reaction.

Additional file 3: Is a video showing HES3 cultured as a monolayer on a LN-coated plate (MNL) and treated with $12 \mu \mathrm{M}$ CHIR99021 at day 0 and $5 \mu \mathrm{M}$ IWP2 at day 3 in RPMI/B27 medium without insulin. Video 1 shows cardiomyocytes from day 20.

Additional file 4: Is a figure showing growth kinetics of MC stirred spinner cultures of (A) HES3 and (B) H7 during the propagation phase. $\mathrm{H7}$ produced larger aggregates than HES3 in PLL + LN MC spinner flask.

Additional file 5: Is a video showing integrated propagation and differentiation of HES3 in MC culture platform (MC-Sp). Video 2 shows cardiomyocytes from day 20 . Round spheres inside the cell clumps are the MCs (diameter $\approx 100 \mu \mathrm{m}$ ).

Additional file 6: Is a figure showing growth kinetics of H7/MC aggregates differentiating in stirred spinner cultures. The cultures were incubated at $37^{\circ} \mathrm{C}$ and $5 \%$ carbon dioxide in stirring conditions, except on day 1 and day 3 , in which the cultures were incubated in static conditions for 16 hours to reduce cell lost due to the addition of Wnt modulators, CHIR99021 and IWP2. Feeding regime is as indicated by arrows.

Additional file 7: Is a table presenting integrated propagation and differentiation of $\mathrm{H7}$ to cardiomyocytes in MC spinner cultures.

Additional file 8: Is a figure showing the dose-dependent effect of E-4031 (A) and verapamil (B) on duration of the QT interval of ReproCardio 2 induced pluripotent stem cell-derived cardiomyocytes using the QTempo assay (conducted by ReproCELL Inc.). Results are presented as actual measurements $(\cdot)$ and after correction with Bazett ( or Fredericia $(\boldsymbol{\Delta})$ formulas. Increase in the E-4031 concentration results in prolongation of QT intervals, while increase in the verapamil concentration results in reduction of QT intervals. 


\section{Abbreviations}

CM: cardiomyocytes (cardiac troponin T-positive cells) in the final cell population; CTnT: cardiac troponin T; EB: embryoid body; FACS: fluorescenceactivated cell sorting; hESC: human embryonic stem cell; hPSC: human pluripotent stem cell; IWP: inhibitor of Wnt production; LN: laminin; MC: microcarrier; MC-AS: hESC/MC aggregates in agitated suspension cultures; MC-Rp: monolayer replated cultures; MC-Sp: hESC/MC aggregates in spinner cultures; MC-SS: hESC/MC aggregates in static suspension cultures; MHC: myosin heavy chain; MNL: monolayer cultures; OCT4: octamer-binding transcription factor 4; PBS: phosphate-buffered saline; PLL: poly-L-lysine; SA: sarcomeric a-actinin.

\section{Competing interests}

The authors declare that they have no competing interests.

\section{Authors' contributions}

AT-LL performed the acquisition, analysis, and interpretation of data, and drafted the manuscript. AK-LC was responsible for designing the study and data analysis. $J$ performed the preparation and coating of microcarriers. WRB and SR were involved in the study design, data analysis, and manuscript writing. SK-WO conceived of the study and participated in its design, as well as critical manuscript revision. All authors read and approved the final manuscript.

\section{Acknowledgements}

The authors thank the Joint Council Office of the Agency of Science and Technology (A*STAR) for funding this project and are grateful to Lim Yu Ming for culture of the hESC cell lines. They also thank Dr Filip Laco for his critical review of this manuscript.

\section{Author details}

${ }^{1}$ Stem Cell Group, Bioprocessing Technology Institute, Agency for Science, Technology and Research (A*STAR), Singapore 138668, Singapore. ${ }^{2}$ Institute of Materials Research and Engineering, Agency for Science, Technology and Research (A*STAR), Singapore 117602, Singapore.

Received: 10 February 2014 Revised: 3 July 2014

Accepted: 9 September 2014 Published: 15 September 2014

\section{References}

1. Kawaguchi N, Nakanishi T: Cardiomyocyte regeneration. Cells 2013, 2:67-82.

2. McMurray JJ, Pfeffer MA: Heart failure. Lancet 2005, 365:1877-1889.

3. Brignier AC, Gewirtz AM: Embryonic and adult stem cell therapy. J Allergy Clin Immunol 2010, 125:S336-S344.

4. Jameel MN, Zhang J: Stem cell therapy for ischemic heart disease. Antioxid Redox Signal 2010, 13:1879-1897.

5. Gersh BJ, Simari RD, Behfar A, Terzic CM, Terzic A: Cardiac cell repair therapy: a clinical perspective. Mayo Clin Proc 2009, 84:876-892.

6. Shiba Y, Hauch KD, Laflamme MA: Cardiac applications for human pluripotent stem cells. Curr Pharm Des 2009, 15:2791-2806.

7. Laflamme MA, Chen KY, Naumova AV, Muskheli V, Fugate JA, Dupras SK, Reinecke H, Xu C, Hassanipour M, Police S, O'Sullivan C, Collins L, Chen Y, Minami E, Gill EA, Ueno S, Yuan C, Gold J, Murry CE: Cardiomyocytes derived from human embryonic stem cells in pro-survival factors enhance function of infarcted rat hearts. Nat Biotechnol 2007, 25:1015-1024.

8. Paige SL, Osugi T, Afanasiev OK, Pabon L, Reinecke H, Murry CE: Endogenous Wnt/beta-catenin signaling is required for cardiac differentiation in human embryonic stem cells. PLoS One 2010, 5:e11134.

9. Tran TH, Wang X, Browne C, Zhang Y, Schinke M, Izumo S, Burcin M: Wnt3a-induced mesoderm formation and cardiomyogenesis in human embryonic stem cells. Stem Cells 2009, 27:1869-1878.

10. Yang L, Soonpaa MH, Adler ED, Roepke TK, Kattman SJ, Kennedy M, Henckaerts E, Bonham K, Abbott GW, Linden RM, Field LJ, Keller GM: Human cardiovascular progenitor cells develop from a KDR + embryonicstem-cell-derived population. Nature 2008, 453:524-528.

11. Graichen $R, X u$ X, Braam SR, Balakrishnan T, Norfiza S, Sieh S, Soo SY, Tham SC, Mummery C, Colman A, Zweigerdt R, Davidson BP: Enhanced cardiomyogenesis of human embryonic stem cells by a small molecular inhibitor of p38 MAPK. Differentiation 2008, 76:357-370.
12. Lian X, Hsiao C, Wilson G, Zhu K, Hazeltine LB, Azarin SM, Raval KK, Zhang J, Kamp TJ, Palecek SP: Robust cardiomyocyte differentiation from human pluripotent stem cells via temporal modulation of canonical Wnt signaling. Proc Natl Acad Sci U S A 2012, 109:E1848-E1857.

13. Lian X, Zhang J, Azarin SM, Zhu K, Hazeltine LB, Bao X, Hsiao C, Kamp TJ, Palecek SP: Directed cardiomyocyte differentiation from human pluripotent stem cells by modulating Wnt/beta-catenin signaling under fully defined conditions. Nat Protoc 2013, 8:162-175.

14. Takahashi T, Lord B, Schulze PC, Fryer RM, Sarang SS, Gullans SR, Lee RT: Ascorbic acid enhances differentiation of embryonic stem cells into cardiac myocytes. Circulation 2003, 107:1912-1916.

15. Yoon BS, Yoo SJ, Lee JE, You S, Lee HT, Yoon HS: Enhanced differentiation of human embryonic stem cells into cardiomyocytes by combining hanging drop culture and 5-azacytidine treatment. Differentiation 2006, 74:149-159.

16. Mummery $C$, Ward-van Oostwaard D, Doevendans $P$, Spijker $R$, van den Brink S, Hassink R, van der Heyden M, Opthof T, Pera M, de la Riviere AB, Passier R, Tertoolen L: Differentiation of human embryonic stem cells to cardiomyocytes: role of coculture with visceral endoderm-like cells. Circulation 2003, 107:2733-2740.

17. Passier R, Oostwaard DW, Snapper J, Kloots J, Hassink RJ, Kuijk E, Roelen B, de la Riviere $A B$, Mummery $C$ : Increased cardiomyocyte differentiation from human embryonic stem cells in serum-free cultures. Stem Cells 2005, 23:772-780.

18. Xu XQ, Graichen R, Soo SY, Balakrishnan T, Rahmat SN, Sieh S, Tham SC, Freund C, Moore J, Mummery C, Colman A, Zweigerdt R, Davidson BP. Chemically defined medium supporting cardiomyocyte differentiation of human embryonic stem cells. Differentiation 2008, 76:958-970.

19. Ying QL, Stavridis M, Griffiths D, Li M, Smith A: Conversion of embryonic stem cells into neuroectodermal precursors in adherent monoculture. Nat Biotechnol 2003, 21:183-186.

20. Hwang YS, Polak JM, Mantalaris A: In vitro direct chondrogenesis of murine embryonic stem cells by bypassing embryoid body formation. Stem Cells Dev 2008, 17:971-978.

21. Kehat I, Kenyagin-Karsenti D, Snir M, Segev H, Amit M, Gepstein A, Livne E, Binah O, Itskovitz-Eldor J, Gepstein L: Human embryonic stem cells can differentiate into myocytes with structural and functional properties of cardiomyocytes. J Clin Invest 2001, 108:407-414.

22. Ng ES, Davis RP, Azzola L, Stanley EG, Elefanty AG: Forced aggregation of defined numbers of human embryonic stem cells into embryoid bodies fosters robust, reproducible hematopoietic differentiation. Blood 2005, 106:1601-1603.

23. Zandstra PW, Bauwens C, Yin T, Liu Q, Schiller H, Zweigerdt R, Pasumarthi $\mathrm{KB}$, Field $\mathrm{L}$ : Scalable production of embryonic stem cell-derived cardiomyocytes. Tissue Eng 2003, 9:767-778.

24. Niebruegge S, Nehring A, Bar H, Schroeder M, Zweigerdt R, Lehmann J: Cardiomyocyte production in mass suspension culture: embryonic stem cells as a source for great amounts of functional cardiomyocytes. Tissue Eng Part A 2008, 14:1591-1601.

25. Chen AK, Reuveny S, Oh SK: Application of human mesenchymal and pluripotent stem cell microcarrier cultures in cellular therapy: achievements and future direction. Biotechnol Adv 2013, 31:1032-1046.

26. Kurosawa $\mathrm{H}$ : Methods for inducing embryoid body formation: in vitro differentiation system of embryonic stem cells. J Biosci Bioeng 2007, 103:389-398.

27. Bauwens CL, Peerani R, Niebruegge S, Woodhouse KA, Kumacheva E, Husain M, Zandstra PW: Control of human embryonic stem cell colony and aggregate size heterogeneity influences differentiation trajectories. Stem Cells 2008, 26:2300-2310.

28. Rajala K, Pekkanen-Mattila M, Aalto-Setala K: Cardiac differentiation of pluripotent stem cells. Stem Cells Int 2011, 2011:383709.

29. Mohr JC, Zhang J, Azarin SM, Soerens AG, de Pablo JJ, Thomson JA, Lyons GE, Palecek SP, Kamp TJ: The microwell control of embryoid body size in order to regulate cardiac differentiation of human embryonic stem cells. Biomaterials 2010, 31:1885-1893.

30. Mohr JC, de Pablo JJ, Palecek SP: 3-D microwell culture of human embryonic stem cells. Biomaterials 2006, 27:6032-6042.

31. Chen AK, Ting S, Seow J, Reuveny S, Oh SK: Considerations in designing systems for large scale production of human cardiomyocytes from pluripotent stem cells. Stem Cell Res Ther 2013, 5:12. 
32. Chen AK, Chen X, Choo AB, Reuveny S, Oh SK: Critical microcarrier properties affecting the expansion of undifferentiated human embryonic stem cells. Stem Cell Res 2011, 7:97-111.

33. Heng BC, Li J, Chen AK, Reuveny S, Cool SM, Birch WR, Oh SK: Translating human embryonic stem cells from 2-dimensional to 3-dimensional cultures in a defined medium on laminin- and vitronectin-coated surfaces. Stem Cells Dev 2012, 21:1701-1715.

34. Oh SK, Chen AK, Mok Y, Chen X, Lim UM, Chin A, Choo AB, Reuveny S: Long-term microcarrier suspension cultures of human embryonic stem cells. Stem Cell Res 2009, 2:219-230.

35. Lam TL, Li J, Chen AK, Reuveny S, Oh SK, Birch WR: Cationic charge with vitronectin or laminin dictate the evolution of $\mathrm{hESC} /$ microcarrier aggregates and cell growth in agitated cultures. Stem Cells Dev 2013, 23:1688-1703.

36. Bardy J, Chen AK, Lim YM, Wu S, Wei S, Weiping H, Chan K, Reuveny S, Oh SK: Microcarrier suspension cultures for high-density expansion and differentiation of human pluripotent stem cells to neural progenitor cells. Tissue Eng Part C Methods 2013, 19:166-180.

37. Choo A, Padmanabhan J, Chin A, Fong WJ, Oh SK: Immortalized feeders for the scale-up of human embryonic stem cells in feeder and feederfree conditions. J Biotechnol 2006, 122:130-141.

38. Lecina M, Ting S, Choo A, Reuveny S, Oh S: Scalable platform for human embryonic stem cell differentiation to cardiomyocytes in suspended microcarrier cultures. Tissue Eng Part C Methods 2010, 16:1609-1619.

39. Chen X, Chen A, Woo TL, Choo AB, Reuveny S, Oh SK: Investigations into the metabolism of two-dimensional colony and suspended microcarrie cultures of human embryonic stem cells in serum-free media. Stem Cells Dev 2010, 19:1781-1792

40. Asai Y, Tada M, Otsuji TG, Nakatsuji N: Combination of functional cardiomyocytes derived from human stem cells and a highly-efficient microelectrode array system: an ideal hybrid model assay for drug development. Curr Stem Cell Res Ther 2010, 5:227-232.

41. Stett A, Egert U, Guenther E, Hofmann F, Meyer T, Nisch W, Haemmerle H: Biological application of microelectrode arrays in drug discovery and basic research. Anal Bioanal Chem 2003, 377:486-495.

42. Halbach M, Egert U, Hescheler J, Banach K: Estimation of action potentia changes from field potential recordings in multicellular mouse cardiac myocyte cultures. Cell Physiol Biochem 2003, 13:271-284.

43. Haws CW, Lux RL: Correlation between in vivo transmembrane action potential durations and activation-recovery intervals from electrograms. Effects of interventions that alter repolarization time. Circulation 1990, 81:281-288

44. Luo S, Michler K, Johnston P, Macfarlane PW: A comparison of commonly used QT correction formulae: the effect of heart rate on the QTc of normal ECGs. J Electrocardio/ 2004, 37:81-90.

45. Martin BL, Kimelman D: Regulation of canonical Wnt signaling by Brachyury is essential for posterior mesoderm formation. Dev Cell 2008, 15:121-133.

46. Zeng AP, Hu WS, Deckwer WD: Variation of stoichiometric ratios and their correlation for monitoring and control of animal cell cultures. Biotechnol Prog 1998, 14:434-441.

47. Blazeski A, Zhu R, Hunter DW, Weinberg SH, Zambidis ET, Tung L: Cardiomyocytes derived from human induced pluripotent stem cells as models for normal and diseased cardiac electrophysiology and contractility. Prog Biophys Mol Biol 2012, 110:166-177.

48. Matsuura K, Wada M, Shimizu T, Haraguchi Y, Sato F, Sugiyama K, Konishi K, Shiba Y, Ichikawa H, Tachibana A, Ikeda U, Yamato M, Hagiwara N, Okano T: Creation of human cardiac cell sheets using pluripotent stem cells. Biochem Biophys Res Commun 2012, 425:321-327.

49. Kehoe DE, Jing D, Lock LT, Tzanakakis ES: Scalable stirred-suspension bioreactor culture of human pluripotent stem cells. Tissue Eng Part A 2010, 16:405-421.

50. Phillips BW, Horne R, Lay TS, Rust WL, Teck TT, Crook JM: Attachment and growth of human embryonic stem cells on microcarriers. J Biotechnol 2008, 138:24-32

51. Murry CE, Keller G: Differentiation of embryonic stem cells to clinically relevant populations: lessons from embryonic development. Cell 2008, 132:661-680.

52. Lev S, Kehat I, Gepstein L: Differentiation pathways in human embryonic stem cell-derived cardiomyocytes. Ann N Y Acad Sci 2005, 1047:50-65.
53. Niebruegge S, Bauwens CL, Peerani R, Thavandiran N, Masse S, Sevaptisidis E, Nanthakumar K, Woodhouse K, Husain M, Kumacheva E, Zandstra PW: Generation of human embryonic stem cell-derived mesoderm and cardiac cells using size-specified aggregates in an oxygen-controlled bioreactor. Biotechnol Bioeng 2009, 102:493-507.

54. Peerani R, Rao BM, Bauwens C, Yin T, Wood GA, Nagy A, Kumacheva E, Zandstra PW: Niche-mediated control of human embryonic stem cell self-renewal and differentiation. Embo J 2007, 26:4744-4755.

55. Wu Y, Ai Z, Yao K, Cao L, Du J, Shi X, Guo Z, Zhang Y: CHIR99021 promotes self-renewal of mouse embryonic stem cells by modulation of proteinencoding gene and long intergenic non-coding RNA expression. Exp Cell Res 2013, 319:2684-2699.

56. Nienow AW: Reactor engineering in large scale animal cell culture. Cytotechnology 2006, 50:9-33

57. Brembeck FH, Rosario M, Birchmeier W: Balancing cell adhesion and Wnt signaling, the key role of beta-catenin. Curr Opin Genet Dev 2006, 16:51-59.

58. Mook RA Jr, Chen M, Lu J, Barak LS, Lyerly HK, Chen W: Small molecule modulators of Wnt/beta-catenin signaling. Bioorg Med Chem Lett 2013, 23:2187-2191.

59. Kinney MA, Sargent CY, McDevitt TC: The multiparametric effects of hydrodynamic environments on stem cell culture. Tissue Eng Part B Rev 2011, 17:249-262.

60. Saha S, Ji L, de Pablo JJ, Palecek SP: Inhibition of human embryonic stem cell differentiation by mechanical strain. J Cell Physiol 2006, 206:126-137.

61. Kallos MS, Behie LA: Inoculation and growth conditions for high-celldensity expansion of mammalian neural stem cells in suspension bioreactors. Biotechnol Bioeng 1999, 63:473-483.

62. Ivanovic Z: Hypoxia or in situ normoxia: the stem cell paradigm. J Cell Physiol 2009, 219:271-275.

63. Varum S, Rodrigues AS, Moura MB, Momcilovic O, CAt E, Ramalho-Santos J, Van Houten B, Schatten G: Energy metabolism in human pluripotent stem cells and their differentiated counterparts. PLoS One 2011, 6:e20914.

64. Mostafa SS, Papoutsakis ET, Miller WM: Oxygen tension modulates the expression of cytokine receptors, transcription factors, and lineagespecific markers in cultured human megakaryocytes. Exp Hematol 2001, 29:873-883.

65. Bell EL, Klimova TA, Eisenbart J, Schumacker PT, Chandel NS: Mitochondrial reactive oxygen species trigger hypoxia-inducible factor-dependent extension of the replicative life span during hypoxia. Mol Cell Biol 2007, 27:5737-5745

66. Lee SY, Jeon HM, Ju MK, Kim CH, Yoon G, Han SI, Park HG, Kang HS: Wnt/Snail signaling regulates cytochrome $\mathrm{C}$ oxidase and glucose metabolism. Cancer Res 2012, 72:3607-3617.

67. Cao N, Liu Z, Chen Z, Wang J, Chen T, Zhao X, Ma Y, Qin L, Kang J, Wei B, Wang $L$, Jin $Y$, Yang HT: Ascorbic acid enhances the cardiac differentiation of induced pluripotent stem cells through promoting the proliferation of cardiac progenitor cells. Cell Res 2012, 22:219-236.

\section{doi:10.1186/scrt498}

Cite this article as: Lam et al:: Conjoint propagation and differentiation of human embryonic stem cells to cardiomyocytes in a defined microcarrier spinner culture. Stem Cell Research \& Therapy 2014 5:110

\section{Submit your next manuscript to BioMed Central and take full advantage of:}

- Convenient online submission

- Thorough peer review

- No space constraints or color figure charges

- Immediate publication on acceptance

- Inclusion in PubMed, CAS, Scopus and Google Scholar

- Research which is freely available for redistribution 